\title{
O DESENVOLVIMENTO CRÍTICO DA VONTADE EM KANT
}

Juliano Fellini*

RESUMO - Segundo Kant, a possibilidade de a razão pura prática efetivamente determinar a vontade depende, inicialmente, de uma profunda investigação da faculdade de desejar na perspectiva de sua filosofia transcendental. A fim de demonstrar isso, apresentaremos neste artigo o desenvolvimento crítico desta faculdade e, com ele, as bases sobre as quais os conceitos de uma boa vontade e de uma razão pura prática se relacionam para a constituição da moralidade.

PALAVRAS-CHAVE - Fundamentação Ética. Moral. Razão e Vontade. Immanuel Kant.
ABSTRACT - According to Kant, the possibility that pure practical reason may effectively determine the will depends, initially, upon an in-depth investigation of the faculty of desire within the perspective of his transcendental philosophy. In order to demonstrate this, we will present in this paper the critical development of this faculty and with it the bases upon which the concepts of a good will and of a pure practical reason relate themselves to the constitution of morality.

KEY WORDS - Ethical Groundwork. Moral. Reason and Will. Immanuel Kant.

A investigação filosófica no âmbito ético sinaliza o advento de um novo elemento constituinte do sujeito racional: a faculdade volitiva. Em Kant, a dinâmica da razão pura prática se resume na determinação racional da vontade para a constituição da moralidade. $O$ objetivo deste artigo é acompanhar a relação da razão e da vontade em Kant para, com isso, entender o processo evolutivo deste conceito, o qual caracterizamos como o desenvolvimento crítico da faculdade de desejar. Para a filosofia transcendental de Kant, não é suficiente uma simples conformidade da vontade com a razão. Somente se a vontade agir por motivos racionais, poderemos falar em moralidade. Situada sob esse projeto crítico, a filosofia moral kantiana exige da vontade uma disposição muito mais radical no seguimento dos princípios racionais. Convém esclarecer que o ponto arquimediano do debate moral em Kant encontra-se já na lei moral, enquanto proposição sintética a priori, e será através dela que a vontade assumirá um contorno crítico. No entanto, por razões metodológicas, o nosso ponto de partida encontra-se na faculdade de desejar, passando pela vontade livre até chegar ao conceito de vontade autônoma. Estas etapas refletem os distintos níveis da relação da vontade com a lei moral.

* Doutor em Filosofia, PUCRS.

\begin{tabular}{|l|l|l|l|l|l|}
\hline VERITAS & Porto Alegre & v. 53 & n. 1 & março 2008 & p. 92-102
\end{tabular}


Ao longo da história da filosofia, o conceito de uma faculdade de desejar foi designado de diferentes maneiras. Platão diferenciou o querer do simples desejo. Em Aristóteles, podemos encontrar uma diferenciação entre razão prática(noûs praktikós) e razão teórica(noûs theoretikós). Por sua vez, os Escolásticos se referem à primeira como intellectus practicus ou como intellectus activus e ratio practica. Os wolffianos mantêm a distinção em sua terminologia de cognitio movens e cognitio iners, e reconhecem tanto elementos cognitivos como impulsivos na faculdade de volição, de modo que a expressam como appetitus rationalis. Em Kant, tal faculdade é denominada de razão prática(praktische Vernunft) ${ }^{1}$. Se, por ora, utilizamos a expressão "faculdade de desejar"(Begehrungsvermögen), o fazemos apenas com intuitos propedêuticos, isto é, pretendemos acompanhar a evolução deste conceito até ao seu máximo desenvolvimento crítico².

No Prefácio da Crítica da Razão Prática, Kant trata a faculdade de desejar em relação ao sentimento de prazer. Ela se define como "o poder (...) de ser, pelas suas representações, causa da realidade dos objectos dessas representações" 3 . 0 sentimento de prazer intervém sobre a faculdade de desejar como "a representação da concordância do objecto ou da ação com as condições subjectivas da vida, isto é, com o poder da causalidade de uma representação em relação à realidade do seu objecto(ou à determinação das forças do sujeito para a acção de o produzir)" " . Aqui encontramos a descrição do que seja propriamente uma ação impulsiva, quando a representação do prazer ou dos impulsos vitais define um objetivo a ser alcançado e move a faculdade de desejar para sua realização. Nesse sentido, a determinação da faculdade de desejar pelo prazer é denominada de apetite, e o apetite habitual é denominado de inclinação. $O$ entendimento pode encontrar uma regra entre tais instâncias (prazer e faculdade de desejar), mas que é válida apenas para o indivíduo. $\mathrm{Na}$ contramão, surge o projeto crítico de Kant de encontrar um fundamento objetivo para a noção de ação voluntária, o que vai de encontro à qualquer fundamentação do tipo hedonista. Daí a introdução do elemento racional como base de determinação da faculdade de desejar.

A definição da razão enquanto faculdade de princípios a priori possibilita a capacidade de agir, não apenas por representações do agradável, ao contrário, podemos agir por representações que estão acima da mera sensibilidade. Esta capacidade de sermos, por meio de uma representação racional, causa dos objetos daquela representação define uma espécie de causalidade pertencente aos seres racionais que dispõem de outro fundamento além do simples impulso. Contudo, como conceber o movimento da faculdade de desejar sem o expediente do impulso, do

1 Cf. BECK, L. W. A Commentary on Kant's Critique of Practical Reason. Chicago and London: The University of Chicago Press, 1984, p. 37.

2 O próprio Kant refere-se a ela inicialmente nestes termos, faculdade de desejar, para acentuar que o seu tratado filosófico não pertence a uma psicologia empírica, mas a uma filosofia transcendental.

3 CRPr A 16.

4 CRPr A 16. 
interesse? A razão possibilita que seus princípios determinem a conduta e se tornem igualmente o seu motivo, o seu interesse, o seu 'impulso'. Por isso, Kant afirmará a existência "de um puro interesse da razão e poderíamos designá-lo como uma inclinação livre dos sentidos (propensio intellectualis)" ${ }^{5}$.

A possibilidade de um puro interesse da razão nos conduz à seguinte distinção: faculdade de desejar inferior e faculdade de desejar superior. A primeira está imediatamente relacionada com um objeto(do prazer) e, como tal, somente pode fornecer regras de ação, mas nenhuma lei moral. $\mathrm{O}$ objeto constitui a matéria da faculdade de desejar e o desejo desse objeto precede a regra prática. 0 problema que ronda tais princípos práticos materiais, que podem ser designados sob o princípio geral do amor de si ou da felicidade pessoal, é a falta de objetividade. Mesmo reunidos sob uma única designação, na realidade eles estão sujeitos à contingência. Por outro lado, a faculdade de desejar superior, que se origina, quando a razão passa a ser considerada como instância de determinação, possibilita a capacidade de agir por outros critérios que não os sensíveis: "A razão pura deve, por si mesma apenas, ser prática, isto é, sem pressuposição de um sentimento qualquer, por conseguinte, sem representações do agradável ou desagradável (...)" 6 .

Desde a primeira Crítica, o empírico mostrou-se sinônimo do contingente, e seu equivalente no âmbito prático são os princípios materiais que se mostram ineficientes enquanto critério objetivo da moralidade. Por isso, Kant quer demonstrar que fundamentos não-racionais não possuem consistência interna, não são necessariamente obrigatórios e nem universais em sua aplicação. Uma ordem moral objetiva jamais poderia ser construída a partir de tais fundamentos. A razão, tanto na esfera teórica quanto prática, serve para sistematizar, integrar e universalizar?. Portanto, dada a inconsistência dos princípios práticos materiais, requer-se que eles sejam excluídos do processo de fundamentação moral.

A razão, então, proporciona uma regra puramente formal válida para todos os seres racionais, sem distinção, o que permite falar de uma faculdade de desejar superior: "Se não existissem leis puramente formais que determinassem suficientemente a vontade, também não poderia admitir-se uma faculdade de desejar superior" ${ }^{8}$. Isso vem ao encontro da necessidade de fundar a teoria moral em termos científicos, no sentido de um fundamento seguro. O filosofar prático não endossa simplesmente aquilo que o senso comum sabe ou como a razão vulgar age; ele vai além e proporciona bases seguras para a questão do moralmente bom. A regra formal da razão, como princípio a priori universal e necessário, constitui-se neste princípio que promete um critério seguro para a solução das questões morais.

Se a determinação da faculdade de desejar, por meio de uma regra formal da razão, constitui um critério objetivo de ação, precisamos encontrar na vontade as

\section{$\mathrm{MC} \mathrm{AB} 4$.}

CRPr A 44, 45.

7 Cf. BECK, L. W. A Commentary on Kant's Critique of Practical Reason. Chicago: The University of Chicago Press, 1984, p. 47.

8 CRPr A 41. 
propriedades que garantem a efetividade dessa determinação. Desse modo, o que nos conduz ao item subseqüente será a questão de como é possível haver uma síntese entre elementos tão díspares como o são razão e faculdade de desejar, 0 que demanda a exposição da liberdade como instância fundamental da dinâmica da razão pura prática.

\section{II}

Como visto anteriormente, a possibilidade de uma faculdade de desejar superior diz respeito ao conceito de vontade, que não é outra coisa senão a própria "faculdade de desejar cujo fundamento determinante - e daí até mesmo o que lhe é agradável se encontra na razão do sujeito(...)" ${ }^{9}$. A condição que permite chegar a tal conceito de vontade é a liberdade.

Desde a Dialética, na primeira Crítica, Kant explora a liberdade sistematicamente associada ao conceito de causalidade e, agora, no interior da filosofia prática não é diferente, uma vez que "a vontade é uma espécie de causalidade dos seres vivos, enquanto racionais, e liberdade seria a propriedade dessa causalidade, pela qual ela pode ser eficiente, independentemente de causas estranhas que a determinem" ${ }^{10}$. No contexto da razão em seu uso teórico, ficou estabelecido que "todas as mudanças acontecem de acordo com o princípio da ligação de causa e efeito" ${ }^{11}$. Daí se depreende que a sucessão dos fenômenos na natureza acontece sempre sob regras: "A natureza inteira em geral nada mais é, na verdade, do que uma conexão de fenômenos segundo regras; e em nenhuma parte há irregularidade alguma" ${ }^{12}$. Estamos falando de uma sucessão objetiva de fenômenos, isto é, da representação de um objeto em geral segundo uma regra universal. Essa regra provém do entendimento que, de uma base a priori, permite afirmar que não há 'irregularidade alguma', ou seja, que os fenômenos se sucedem um ao outro na relação de causa e efeito necessariamente.

É interessante notar que, na análise do conceito de causalidade, outros conceitos estão aí implicados: "Esta causalidade leva ao conceito de ação, esta última ao conceito de força e, desse modo, ao conceito de substância" ${ }^{13}$. Kant quer chamar a atenção para o conceito de substância, não tanto pela característica da permanência, mas por sua propriedade ativa, isto é, de produzir ações. No entanto, a causalidade, a partir do modelo da substância, não afirma a ação como um começo a partir dela mesma. Há um fundamento de determinação que está para além da substância mesma e que se explica pelo determinismo natural. A ação, enquanto causa das mudanças no mundo, não se diferencia em nada da ação humana e ambas nos aparecem como simples processos da natureza, pois a diferença entre as ações naturais e a ação humana não se deixa perceber nos seus efeitos, mas na propriedade de 0 agente racional ser uma 'causa incausada'. É neste ponto específico, de afirmar

\footnotetext{
$\mathrm{MC} A B 5$.

10 FMC BA 97.

1 CRP B 233.

12 L A 1.

13 CRP A 204 B 249.
} 
uma causalidade livre, que se concentram os esforços na busca de um fundamento de determinação da ação para além do paradigma teórico ${ }^{14}$.

Com isso, retorna à pauta a problemática condição de um conceito para o qual a razão, em seu uso teórico, se vê incapaz de apresentar uma solução definitiva, pois "não basta verificá-la por certas supostas experiências da natureza humana (...), mas sim temos que demonstrá-la como pertencente à actividade de seres racionais em geral e dotados de uma vontade" ${ }^{15}$. O que gera uma especial dificuldade é encontrar uma base para afirmar que determinados efeitos são procedentes de uma ação, a partir de uma causalidade livre. Em se tratando de uma ação em sentido teórico, temos a possibilidade de, pelo encadeamento físico, chegar à causa, pois esta é de natureza sensível. Em sentido prático, nos deparamos com uma dificuldade irredutível: encontrar sob determinados efeitos sensíveis uma causa supra-sensível. Contudo, esse procedimento já foi dispensado por Kant, pois tal conceito se define e se resolve apenas aprioristicamente, e "a experiência unicamente nos dá a conhecer a lei dos fenômenos, por conseguinte, o mecanismo da natureza, que constitui precisamente 0 contrário da liberdade" ${ }^{16}$.

Diante disso, Kant busca a idéia da liberdade a partir de nossa condição de seres racionais. $O$ fato de possuirmos a faculdade da razão, ainda que em sentido teórico, denota a existência de uma 'pura atividade própria', o que demonstra que não nos constituímos simplesmente de sensibilidade receptiva. Na consciência de nossa espontaneidade epistêmica estamos diretamente conscientes de uma capacidade que nos subtrai aos condicionamentos sensíveis ${ }^{17}$. Assim, podemos afirmar que a prova da liberdade se daria no próprio agir, visto que é acompanhado de uma autoconsciência que exclui a subordinação às causas naturais. A liberdade pode ser compreendida no agir próprio e voluntário, pois, pela decisão, posso perceber que as causas subalternas da natureza são superadas, dada a consciência que tenho de começar algo a partir de mim mesmo. 0 agir humano se distingue de todas as demais ações na natureza, porque vem acompanhado desta autoconsciência. $\mathrm{O}$ ato que brota de mim procede da espontaneidade de um 'eu que pensa' e que não é uma simples reação a outro ato qualquer, o que permite assumir outra perspectiva quando da reivindicação da liberdade: a perspectiva de um 'eu' não simplesmente sujeito aos fluxos naturais. Pela perspectiva natural, a liberdade pareceria um autoengano. Contudo, da perspectiva do próprio agir, não há como não me conceder tal propriedade, a de ser livre: sem ela, o próprio agir não se deixaria compreender ${ }^{18}$.

A associação do agir à idéia da liberdade é de tal forma intrínseca que, se alguém mentir, e, com isso, trouxer uma certa desordem à sociedade, nenhuma justificação de ordem empírica (má educação, más companhias, má índole, circunstâncias) se sustenta diante do fato de se tratar de uma ação voluntária e que poderia, não

\footnotetext{
14 Ver: WILLASCHEK, M. Praktische Vernunft: Handlungstheorie und Moralbegründung bei Kant. Stuttgart/ Weimar: J. B. Metzler, 1992.

15 FMC BA 100.

16 CRPr A 53.

17 Cf. ALLISON, H. E. Kant's Theory of Freedom. New York: Cambridge University Press, 1995, p. 222.

18 Cf. GERHARDT, V. Immanuel Kant - Vernunft und Leben. Stuttgart: Reclam, 2002, p. 197s.
} 
obstante todas as condições empíricas, ser de outro modo, pois "a ação é atribuída ao carácter inteligível do autor"19. O caráter inteligível, ao qual Kant se refere, diz respeito ao "Eu tal como ele seja constituído em si(...), aquilo que chega à consciência, não por afecção dos sentidos, mas imediatamente" ${ }^{20}$. A partir daí, podemos compreender o levantar-se da cadeira como uma resolução que não é produto somente de uma seqüência natural. A causalidade humana situa-se em meio aos determinismos, mas não deriva deles simplesmente. A característica da inteligibilidade é o que define a personalidade do sujeito prático, e as condições da moralidade devem ser buscadas aí, no caráter inteligível daquele que se faz a pergunta 'o que devo fazer'.

Dessa maneira, Kant garante a possibilidade de vislumbrar tal princípio em meio ao determinismo natural, sem que isso signifique qualquer contradição ${ }^{21}$. 0 caráter inteligível permite a independência humana relativamente aos impulsos naturais ou simplesmente sua espontaneidade. Do que foi posto, podemos concluir que a liberdade melhor se define enquanto uma propriedade negativa da vontade a qual, entendida como arbítrio (Willkür), tem a possibilidade de fazer escolhas por critérios racionais. No entanto, uma completa determinação do problema moral requer uma determinação mais positiva para a questão da liberdade. Saber que se é livre para agir não é ainda suficiente, enquanto não se determinar precisamente 'como se deve agir', o que vem a ser a questão central da moralidade.

\section{III}

Kant deixa suficientemente claro que a liberdade não significa a ausência de leis ou a mera capacidade de se subtrair aos determinismos naturais. Saber que se é livre das determinações naturais é, sem dúvida, fundamental como condição de possibilidade de uma teoria moral. Entretanto, saber 'como agir', o que vem a ser tão ou mais importante, requer leis que dêem um direcionamento à práxis humana. Kant afirma que "a liberdade (...) nos transfere para uma ordem inteligível das coisas" 22 . Por conseguinte, é nessa ordem inteligível das coisas que devemos buscar esta espécie particular de lei que nos permitirá entender o conceito de autonomia.

$\mathrm{Na}$ segunda Crítica, Kant determinará o mundo inteligível a partir de uma analogia com o mundo sensível. Se podemos definir a natureza como a existência das coisas sob leis empíricas, o que, para a razão, significa heteronomia, podemos também definir uma natureza suprasensível nos mesmos moldes, apenas diferenciando suas leis como independentes da condição sensível e que pertencem à autonomia da razão. A idéia de um mundo supra-sensível constitui uma natureza arquetípica da qual nos é dado conhecer uma lei.

19 CRP A 555 B 583.

20 FMC BA 107.

21 Segundo Kant, "a reunião da causalidade, como liberdade, com a causalidade enquanto mecanismo da natureza, estabelecendo-se a primeira pela lei moral e a segunda mediante a lei natural, num só e mesmo sujeito, o homem, é impossível, sem representar este, na relação à primeira, como ser em si mesmo, mas relativamente à segunda como fenômeno, aquele na consciência pura, este na consciência empírica. Sem isso é inevitável a contradição da razão consigo mesma"(CRPr A 10, 11).

22 CRPr A 72. 
Com isso remontamos à idéia da razão como faculdade de princípios. Em termos práticos, "a razão ocupa-se dos princípios determinantes da vontade, a qual é uma faculdade (...) de produzir objectos correspondentes às representações (...), isto é, de determinar a sua causalidade" 23 . A vontade não apenas pode contemplar-se como independente das condições empíricas, mas também sob a ordem de uma legislação racional manifesta no 'fato da razão' enquanto consciência da lei moral. Esta lei é expressão do eu numênico, superior à sensibilidade, que assegura, não somente 0 uso prático da razão, mas a vontade (Wille) num sentido plenamente crítico, o que leva Kant a afirmar que "vontade livre e vontade submetida a leis morais são uma e a mesma coisa" ${ }^{24}$. Essa identificação entre a faculdade racional e a faculdade volitiva é a tradução do conceito de vontade autônoma.

A autonomia significa dispor de uma regra racional para o discernimento moral e também tomar interesse por ela como o motivo exclusivo da ação. Nesse sentido, a razão deve ser também capaz de causar um interesse suficiente no agir moral e de restringir quaisquer outras oposições advindas da sensibilidade. Nisso podemos encontrar duas funções para a razão pura prática: uma cognitiva, quando determina como deve ser a ação, e outra volitiva, quando motiva a ação por si mesma. Em suma, a autonomia trata de nossa habilidade e responsabilidade para saber o que a moralidade requer de nós e a nossa determinação a agir moralmente ${ }^{25}$.

A principal característica que deve definir e causar interesse por uma regra é a sua universalidade. Este será um dos pontos principais sobre o qual Kant insistirá ao longo de toda sua filosofia prática:"Não escolher senão de modo a que as máximas das escolhas estejam incluídas simultaneamente, no querer mesmo, como lei universal" ${ }^{26}$. Contudo, da percepção do ser racional humano tais determinações chegam na forma de um dever, "pois que a vontade está colocada entre o seu princípio

23 CRPr A 29, 30.

24 FMC BA 99.

25 Segundo Henrich, há dois momentos específicos que constituem a autonomia da razão. 0 primeiro deles diz respeito ao reconhecimento de ações que podem ser qualificadas como racionais. Podemos chegar a esse discernimento a partir dos princípios contidos na própria razão (principium diiudicationis bonitatis). $\mathrm{O}$ segundo refere-se à capacidade que a razão tem de realizar ações, ou seja, como causalidade produzir efeitos (principium executionis bonitatis). Ver: HENRICH, D. Ethik der Autonomie. In: HENRICH, D. Selbstverhältnisse. Stuttgart: Reclam, 2001, p. 6-56.

26 FMC BA 87 O'Neill chama a atenção para a questão do que realmente significa uma vontade autônoma: se a vontade que age tão-somente a partir de si mesma ou se a vontade que age de acordo com uma lei universal. $\mathrm{O}$ primeiro sentido refere-se à liberdade em sentido negativo, quando o agente contempla-se independente das influências externas. Nesse caso, o agir autônomo se definiria apenas como a ação que tem por referência a legislação própria do agente, e nisso não está contida ainda a idéia uma legislação que possa ser adotada por todos. Se permanecêssemos apenas com esta definição de autonomia, as conseqüências poderiam ser contrárias àquelas pretendidas por Kant. No entanto, o segundo sentido de uma vontade autônoma vem definir o critério de uma legislação própria: a que deve valer para todos os outros. Assim, uma vontade autônoma segue sendo a autolegislação do agente, contudo, no horizonte da universalidade, ou seja, com referência àquilo que todos os demais seres racionais devem também querer. Por conseguinte, a capacidade de autolegislação não degenera para o sentido de arbitrariedade, dado que ela se define sob a concepção de uma razão pura prática universal (cf. O'NEILL, O. Autonomy and the Fact of Reason in the Kritik der praktischen Vernunft. In: HÖFFE, O. (Org.) Immanuel Kant - Kritik der praktischen Vernunft. Berlin: Akademie Verlag, 2002, p. 81-97). 
a priori, que é formal, e o seu móbil a posteriori, que é material" ${ }^{27}$. Esta condição da vontade implica, muitas vezes, um déficit motivacional a ser compensado pelo imperativo da razão.

Logo, o que num primeiro momento tratamos por leis da liberdade, aparece agora definido como prescrições da razão que ordenam um 'dever-ser'. Da perspectiva de nossa natureza sensível há uma realidade regida por leis naturais que explicam 0 que já 'é', e isso pode ser determinado pela ciência. Da perspectiva de nossa natureza inteligível há uma realidade a ser constituída pelas leis da liberdade que apontam para um 'dever-ser', e disso se ocupa a filosofia moral. Como se trata de uma realidade a ser constituída, suas leis são na sua forma prescrições, e o fato de possuirmos as condições para agir autonomamente não elimina a tensão interna à natureza humana que percebe a lei da razão sob a forma do dever. Isso, entretanto, não impede que a ação humana possa estar de acordo com o dever desde a sua intenção.

Aqui podemos conceber o conceito da vontade boa como designação para a vontade autônoma. Uma primeira característica atribuível à vontade boa é a de que o seu princípio de determinação deve ser a priori ou formal. Este princípio define apenas a forma do querer em geral, sem levar em conta o objeto e os desejos envolvidos na ação, pois estes apenas validam o querer de um ponto de vista particular. Tal processo assegura uma vontade exclusivamente determinada pela forma de uma lei universal, de modo que entre o querer e a lei moral não permaneça nenhum móbil sensível. Por conseguinte, o valor da ação "não depende da realidade do objecto da acção, mas somente do princípio do querer segundo o qual a acção, abstraindo de todos os objectos da faculdade de desejar, foi praticada" ${ }^{28}$.

Outra característica pode ser encontrada na afirmação de que "uma acção praticada por dever tem o seu valor moral, não no propósito que com ela se quer atingir, mas na máxima que a determina" ${ }^{29}$. Através disso, fica estabelecido também que a ação deve abstrair de todo e qualquer fim que, por meio dela, se queira realizar. A matriz deontológica da moral kantiana busca garantir que nada, além da lei moral, venha a se afirmar como critério de moralidade, se quisermos falar em um valor incondicional que "não pode residir em parte alguma senão no princípio da vontade, abstraindo dos fins que possam ser realizados por tal acção" ${ }^{30}$.

\footnotetext{
FMC BA 14.

8 FMC BA 13.

29 FMC BA 13.
}

30 FMC BA 14. As características do Imperativo Categórico sempre conduziram os intérpretes de Kant a classificar sua moral como deontológica. A ação por puro dever, a permanência da pura forma da lei, nenhuma referência a fins na determinação da vontade: todas essas idéias sedimentaram uma concepção acerca dos princípios morais kantianos que, recentemente, vem sendo desconstruída por alguns de seus comentadores que não mais o referem unicamente ao deontologismo moral, mas ampliam a perspectiva, direcionando-a para os aspectos teleológicos ou para uma teoria dos valores presentes na filosofia moral kantiana. Ver: HORN, C. "Wille, Willensbestimmung, Begehrunsvermögen". In: HÖFFE, O. (Org.) Immanuel Kant-Kritik der praktischen Vernunft. Berlin: Akademie Verlag, 2002, p. 43-61. ; HERMAN, B. The Practice of Moral Judgment. Cambridge MA: Harvard University Press, 1993; e também SCHÖNECKER, D. ; ALLEN, A. W. Kants „Grundlegung zur Metaphysik der Sitten“ - Ein einführender Kommentar. Paderborn/ München/Wien/Zürich: Ferdinand Schöningh, 2002. 
A contrapartida positiva da ação moral como abstração de um objeto e de um fim é o dever como "a necessidade de uma ação por respeito à lei" ${ }^{31}$. Se, por um lado, a lei moral causa dano ao amor-próprio, por outro, ela infunde nesse mesmo ser um sentimento positivo: o respeito. Esta é a conseqüência gerada no indivíduo que declina de todas as inclinações por reconhecer na lei da razão um princípio superior, que conduz sua existência enquanto sujeito prático: "Aquilo que eu reconheço imediatamente como lei para mim, reconheço-o com um sentimento de respeito que não significa senão a consciência da subordinação da minha vontade a uma lei" ${ }^{32}$. Com 0 sentimento de respeito, temos a possibilidade de um aliado sensível contribuir para a determinação da vontade pela razão, 0 que não implica qualquer contradição, visto que é produto dela mesma. Se o interesse demanda necessariamente um elemento sensível, este é dado pela razão quando na vontade já nada mais resta do que a forma da lei universal e o reconhecimento da superioridade da natureza racional: "Todo o chamado interesse moral consiste simplesmente no respeito pela lei" ${ }^{33}$. Esse sentimento é a manifestação fenomênica de uma razão pura prática efetivamente atuando no ser racional finito.

Com isso, encerra-se o processo de fundamentação das condições que nos permitem chegar ao conceito de uma vontade boa ou autônoma: "A necessidade das minhas ações por puro respeito à lei prática é o que constitui o dever, perante 0 qual tem de ceder qualquer outro motivo, porque ele é a condição de uma vontade boa em si, cujo valor é superior a tudo" ${ }^{34}$. Se o uso prático da razão refere-se à relação de uma razão pura com a vontade, pudemos acompanhar o desenvolvimento deste conceito até às últimas conseqüências da filosofia transcendental kantiana, que o eleva de uma simples faculdade de desejar à noção de uma vontade boa.

\section{Considerações Finais}

O processo de fundamentação do princípio supremo da moralidade em Kant não pode ser esgotado se, inicialmente, suas condições não forem verificadas e, elas próprias, fundamentadas. Em última análise, tais condições somente encontram um termo no próprio horizonte da moralidade, enquanto âmbito dos juízos sintéticos a priori práticos. Por questões metodológicas, temos acompanhado o conceito da vontade desde a sua definição 'pré-crítica', enquanto simples faculdade de desejar, passando desta para a vontade livre e, por fim, chegando ao conceito plenamente crítico da vontade boa, o qual só é possível de ser vislumbrado no horizonte da legislação moral. Logo, a moralidade não é uma derivação analítica de suas condições de possibilidade. Ao contrário, a lei moral, enquanto proposição sintética a priori, traz consigo a sua própria realidade na qual o conceito de uma vontade plenamente crítica também se realiza. Portanto, o conceito de vontade autônoma é a conclusão

\footnotetext{
31 FMC BA 14.

32 FMC BA 16.

33 FMC BA 17.

34 FMC BA 20.
} 
que se segue, quando já se está de posse da resposta à pergunta 'o que devo fazer', e não sua condição prévia.

No entanto, a vontade à qual nos referimos, continua sendo humana, o que demanda das leis da razão a forma de um dever. Num sentido negativo, Kant tem por pressuposto, na sua filosofia moral, um entendimento geral das leis da natureza humana ou da antropologia. Apesar disso, o conceito da vontade, associado ao da liberdade, permite que tais interesses possam ser suplantados, mas o que não pode ser suplantado é a própria vontade enquanto considerada sob seus aspectos sensíveis. A forma imperativa da lei da razão é um atestado de que Kant não negligencia a vontade sob seus aspectos sensíveis, mas também não a reduz a uma faculdade empírica. $O$ filósofo de Königsberg acentua que tais aspectos não são determinantes e que a vontade, ao se subtrair deles, pode agir por motivos racionais. Se, exclusivamente, isso é o que não se pode verificar pela experiência. No entanto, para o desenvolvimento crítico da faculdade de desejar, é suficiente saber que a vontade possui as propriedades necessárias para uma determinação a priori pelos princípios da razão.

Nesse contexto surge a questão da motivação moral. Ao longo da Fundamentação, Kant mostra o respeito como a expressão do interesse que podemos tomar pela lei moral e afirma que o princípio objetivo do querer é também o seu motivo. É preciso tornar concebível, dentro da estrutura da filosofia prática kantiana, a presença de um elemento sensível, se quisermos conceber sua filosofia prática como efetiva. Alguns comentadores se referem à razão kantiana como escrava dos impulsos, mas uma escrava inteligente que guia seu patrão de acordo com seu projeto crítico. Sem um elemento sensível, não podemos falar em motivação moral, e a razão pura prática não teria êxito na constituição da moralidade. Por isso, a razão produz o sentimento de respeito a partir da lei moral. A investigação kantiana quer ser completa, quando associa à questão 'o que devo fazer' outra tão importante 'por que agir moralmente', pois as considerações éticas possuem o seu valor, quando, além de proporcionar em um fundamento filosófico seguro, movem a vontade à ação.

\section{Referências}

ALLISON, H. E. Kant's Theory of Freedom. New York: Cambridge University Press, 1995.

BECK, L. W. A Commentary on Kant's Critique of Practical Reason. Chicago and London: The University of Chicago Press, 1984.

GERHARDT, V. Immanuel Kant - Vernunft und Leben. Stuttgart: Reclam, 2002.

HENRICH, D. Ethik der Autonomie. In: HENRICH, D. Selbstverhältnisse. Stuttgart: Reclam, 2001, p. 6-56.

HERMAN, B. The Practice of Moral Judgment. Cambridge MA: Harvard University Press, 1993

HORN, C. "Wille, Willensbestimmung, Begehrunsvermögen". In: HÖFFE, O. (Org.) Immanuel Kant - Kritik der praktischen Vernunft. Berlin: Akademie Verlag, 2002, p. 43-61.

KANT, I. A Metafísica dos Costumes. Trad. Edson Bini. Bauru/SP: EDIPRO, 2003. 
. Crítica da Razão Prática. Trad. Artur Morão. Lisboa: Edições 70, 1989.

. Crítica da Razão Pura. 5.ed. Trad. Manuela P. dos Santos e Alexandre F. Morujão. Lisboa: Fundação Calouste Gulbenkian, 2001.

Edições 70, 2000.

Fundamentação da Metafísica dos Costumes. Trad. Paulo Quintela. Lisboa: . Lógica. Trad. Guido Antônio de Almeida. Rio de Janeiro: Tempo Brasileiro, 1992.

. Werke in sechs Bänden. Hrsg. Wilhelm Weischedel. Darmstadt: Wissenschaftliche Buchgesellschaft, 2005.

O'NEILL, O. Autonomy and the Fact of Reason in the Kritik der praktischen Vernunft. In: HÖFFE, O. (Org.) Immanuel Kant - Kritik der praktischen Vernunft. Berlin: Akademie Verlag, 2002, p. 81-97.

SCHÖNECKER, D. ; ALLEN, A. W. Kants "Grundlegung zur Metaphysik der Sitten" - Ein einführender Kommentar. Paderborn/München/Wien/Zürich: Ferdinand Schöningh, 2002.

WILLASCHEK, M. Praktische Vernunft: Handlungstheorie und Moralbegründung bei Kant. Stuttgart/Weimar: J. B. Metzler, 1992. 